\title{
DE VERKLARING VAN OORDEELONTHOUDING
}

\author{
door Drs. L. J. M. Roozen
}

\section{Inleiding}

De verklaring van oordeelonthouding is onder de Gedrags- en beroepsregels registeraccountants (GBR) in het bijzonder geregeld in de artikelen 12 (leden 1 en 2), 13 (lid 4 ) en 14 (lid 3).

Daaruit blijkt:

a. dat (ook) deze verklaring betrekking heeft op de verantwoording (inclusief toelichtingen) als geheel;

$b$. dat zij een alternatief is van vier limitatief opgesomde verklaringen van verschillende strekking;

c. dat de keuze niet willekeurig is;

d. dat aan haar woordelijke inhoud bepaalde eisen zijn gesteld.

De invoering van de oordeelonthouding in de GBR is een nieuwigheid ten opzichte van de voorgaande beroepsregelen. Daarmee samenhangende is het begrip ,verklaring" principieel gewijzigd: in de plaats van de mededeling (hetzij mondeling of schriftelijk) waarin een oordeel is vervat, is gekomen de (uitsluitend schriftelijke) mededeling omtrent de ,uitkomst”, d.i. het resultaat van onderzoekingsarbeid. Als dit resultaat negatief is, d.w.z. niet heeft geleid tot een stellig oordeel (over de getrouwheid van een verantwoording als geheel), volgt een ,,verklaring van oordeelonthouding".

Door deze tour de force is de illegaliteit van deze reeds lang in zwang zijnde mededelingen (het „,oordeel" dat er geen oordeel is) weggenomen.

Tegenover het voordeel van aanpassing aan de gegroeide praktijk staat het onmiskenbare nadeel van een verarming van het begrip ,,verklaring” en daarmede van de openbare functie.

$\mathrm{Nu}$ deze beslissing echter is gevallen, is het van belang het nieuwe alternatief van de verklaring naar strekking en vorm nader te overwegen. Verwacht moet nl. worden - en in de praktijk is het reeds gebleken - dat van de oordeelonthouding een ruim gebruik zal worden gemaakt. Bovendien rijzen bij deze verklaring, vanwege haar nog steeds gekunsteld karakter, de moeilijkste problemen.

\section{Non-opinion en non-audit}

Behalve de vier alternatieven voor de verklaring, t.w.

1 de goedkeurende;

2 de goedkeurende onder voorbehoud;

3 de afkeuring;

4 de oordeelonthouding, ook wel ,non-opinion" genoemd, is er met betrekking tot de ,mededelingen" (artikel 11 GBR) aangaande een verantwoording nog een vijfde alternatief, t.w. de mededeling omtrent de uitkomst van opgedragen administratieve en/of fragmentarische controlewerkzaamheden - ten behoeve van de opstelling ener verantwoording -, die niet zijn gericht op de verstrekking van een mededeling inzake de getrouw-

$m a b$ blz. 282 
heid van die verantwoording als geheel.

Aan deze ,non-audit", in de V.S. ook wel bekend onder de naam ,,writeup", ware een aparte beschouwing te wijden, waarbij de nadruk zou moeten vallen op de noodzakelijkheid en de mogelijkheid van een scherpe onderscheiding met de verklaring, in het bijzonder met de verklaring van oordeelon thouding.

\section{De wet op de jaarrekening van ondernemingen (WJO)}

In artikel $8 \mathrm{WJO}$ is sprake van een verplichte overlegging van een ,verklaring" door de ,deskundige" die volgens andere wetten met het onderzoek van de jaarrekening is belast.

De wet verwijst niet naar de GBR, zodat de formele vraag kan rijzen of de WJO met ,verklaring" hetzelfde bedoelt als de GBR.

Aangezien ook de WJO de verklaring koppelt aan het onderzoek, kan ,verklaring" niet méér betekenen dan in de GBR. Met name kan met een non-audit mededeling niet worden voldaan aan het voorschrift van de WJO.

Kan het wettelijk begrip enger zijn dan in de GBR, met name: - valt de non-opinion er wel of niet onder? M.i. wèl, indien wij de waarborg van de beperkende bepalingen in artikel 13, lid 4, GBR in het oog houden: ook de wetgever zal objectieve verhinderingen moeten eerbiedigen; hij kan niet het onmogelijke verlangen.

Hier zal de jurisprudentie zekerheid moeten verschaffen.

\section{Een al ternatief, doch niet willekeurig}

Het verband tussen de hiervoren sub 2 tot en met 4 genoemde alternatieven voor de verklaring wordt gelegd door de begrippen „,bedenkingen” en ,onzekerheden" (artikel 13 GBR).

Uiteraard is hier sprake van bedenkingen en onzekerheden, die na het onderzoek zijn blijven bestaan en die van zodanig gewicht zijn, dat een goedkeuring-sec (van de verantwoording als geheel) niet mogelijk is.

Het verband kan worden weergegeven door het volgende schema.

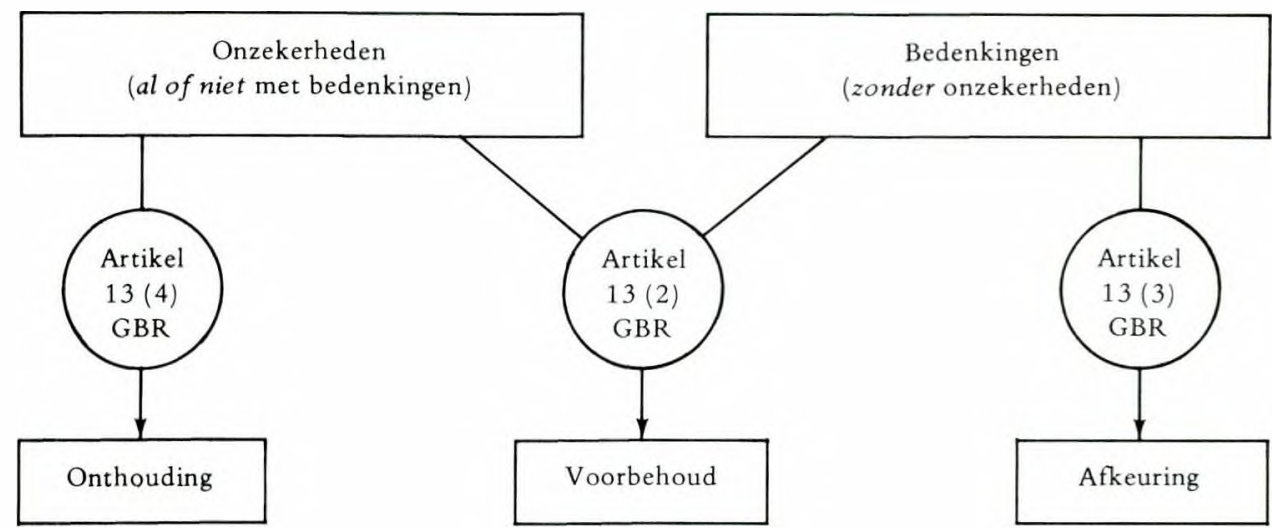

mab blz. 283 
Volgens het vorenstaande schema:

a. kunnen onzekerheden leiden tot een onthouding of tot een voorbehoud;

$b$. kunnen bedenkingen leiden tot een afkeuring of tot een voorbehoud;

c. kan een voorbehoud voortvloeien uit onzekerheden en/of bedenkingen;

$d$. kan een afkeuring alléén voortvloeien uit bedenkingen zonder onzekerheden.

Van deze rich tlijnen vergt alleen die sub $d$ een nadere motivering.

Ik heb dit punt reeds aangesneden in mijn bijdrage: „De verklaring bij verbreking van de continuiteit". De daar getrokken conclusie dat bedenkingen niet kunnen leiden tot een afkeuring indien zich tevens onzekerheden voordoen, heeft een algemene strekking. Hier volgt nog eens een samenvatting van mijn argumenten.

1 Elke verklaring heeft betrekking op de verantwoording als geheel.

2 Onzekerheden strekken zich ipso facto uit tot de verantwoording als geheel.

3 Derhalve kunnen bedenkingen niet leiden tot een andere verklaring dan de oordeelonthouding, als zich tevens onzekerheden voordoen.

4 De afkeuring is een stellige verklaring en impliceert als zodanig een toetsing aan de getrouwe verantwoording.

5 Artikel 13, lid 4, eerste volzin bevestigt het sub 3 en 4 gestelde, door de oordeelonthouding een plaats te geven ingeval ,geen goedkeurend of afkeurend oordeel" kan worden uitgesproken.

6 Artikel 13, lid 4, achter het tweede streepje, kan daarna alleen slaan op de gevallen, waarin zich uitsluitend bedenkingen voordoen: de accountant mag zich dan niet achter een oordeelonthouding verschuilen.

7 De ,zwaardere” strekking van de afkeuring ten opzich te van de oordeelon thouding betekent niet dat zij moet prevaleren, maar juist dat zij met grotere omzich tigheid moet worden gehanteerd.

\section{Objectieve verhinderingen}

Artikel 13, lid 4, GBR verbiedt (achter het eerste streepje) een verklaring van oordeelonthouding af te geven, indien de onzekerheden haar oorzaak vinden in ,,beperkingen bij let onderzoek die niet voortvloeien uit objectieve verhinderingen".

In „Behandeling" ) (blz. 167) wordt ,,in het algemeen” opgemerkt dat het „object" in de term ,objectief" slaat op de desbetreffende huishouding en de organisatie die daar - qua aard en omvang van die huishouding - bij behoort.

Het komt mij voor dat het begrip ,objectief” in dit verband een ruimere inhoud heeft en moet hebben.

Objectief slaat niet op een bepaald object, maar houdt de negatie in van subjectief, waarbij de subjecten zijn: de verantwoordingsplichtige en de accountant:

a. Wat de verantwoordingsplichtige betreft: van hem mag worden verwacht, dat hij:

\footnotetext{
1) „Van R.B.R. tot GBR. De behandeling enz."; uitgave NIVRA
} 
1 aan het onderzoek door de accountant alle medewerking verleent, dit onderzoek althans niet belemmert;

2 een administratieve organisatie (inclusief interne controle) voert, die tenminste voldoet aan de eisen, die daaraan ten behoeve van zijn eigen leiding zijn te stellen;

3 dat hij zelf zijn verantwoording (jaarrekening) opstelt resp. doet opstellen;

4 dat hij zich niet mengt in het controleprogramma van de accountant (al of niet onder het voorwendsel van kostenbesparing).

b. Voor de accountant geldt:

1 dat hij niet, uit concurrentie- of andere subjectieve overwegingen, werkzaamheden nalaat, die voor de vorming van zijn oordeel onmisbaar zijn;

2 dat hij de aanvullende controlewerkzaamheden verricht, die noodzakelijk zijn, doordat administratieve organisatie en/of interne controle tekort schieten of omdat de verantwoording ( $\mathrm{nog}$ ) niet door de verantwoordingsplich tige gereed is gemaakt;

3 dat hij geen eisen stelt aan de administratie en aan de interne controle, uitsluitend ten behoeve van zijn controle.

In verband met het begrip ,objectieve verhinderingen" zijn de sub a 2 en 3 en $b 2$ en 3 vermelde eisen niet absoluut doch onderling afhankelijk.

Zo kan een onvoldoende administratieve organisatie en/of in terne controle (a 2) veelal worden opgevangen door aanvullende controlemaatregelen (b 2) of kunnen de kosten van een verbetering sub a 2 geringer zijn dan de besparing van de kosten van aanvullende werkzaamheden.

Reeds hieruit volgt, dat een oordeelonthouding niet kan steunen op het algemene motief van gebreken in de administratie en/of de interne controle, noch op de aard en omvang van het bedrijf (zoals in allerlei combinaties en formuleringen veelal geschiedt).

Op deze conclusie kom ik hierna in ander verband terug.

Leidt het overleg tussen accountant en verantwoordingsplichtige niet tot overeenstemming en zou de laatste niet voldoen aan de sub a 1 en 4 gestelde eisen, dan rest de accountant slechts, de opdracht te weigeren of terug te geven.

Tot zover geeft het begrip „objectieve verhinderingen” geen grote moeilijkheden.

Echte problematiek rijst eerst op uit de koppeling van het begrip „objectieve verhinderingen" aan ,,beperkingen van het onderzoek”.

Onder deze beperkingen (voortvloeiende uit objectieve verhinderingen) is uiteraard te verstaan, dat een of meer onderdelen van het controleprogramma, die vaktechnisch noodzakelijk zijn om tot een stellig (goedkeurend of afkeurend) oordeel over de getrouwheid van de verantwoording als geheel, te komen, ach terwege zijn gebleven.

Hiermede wordt de vaktechniek in haar volle omvang en in alle bijzonderheden binnengehaald!

Van deze vaktechnische achtergrond wil ik één algemeen aspect bespreken, omdat het rechtstreeks verband houdt met een veelal aangetroffen motive- 
ring c.q. formulering van de non-opinion.

Hiervoor - en ook in het algemeen - is het nuttig een oude tegenstelling van stal te halen, nl. die tussen de verbandscontrole en de controle door middel van het steunen op de interne controle (min of meer gelijk aan die tussen resp. de zgn. ,synthetische" en de ,,analy tische" methode).

Prof. G. Diephuis stelt in de Bedrijfseconomische Encyclopedie (2e druk onder ,Interne controle"),

„,dat de nieuwere inzichten met betrekking tot de inhoud van de vaktechnische eisen (onderzoek naar de kwaliteit van de administratie en interne controle, mede ondersteund door de uitkomsten van mathematische steekproeven) wel definitief in brede kringen van het beroep zijn aanvaard, nu sinds ruim tien jaren geen principiële kritiek op deze opvattingen is gehoord."

Deze bewcring gaat m.i. te ver, indien daarmee is bedoeld, dat de nieuwe methode in de plaats is getreden van de "klassieke" methode der verbandscontrole. Ziet men minder naar hetgeen hierover is gepubliceerd dan naar wat in de praktijk geschiedt, dan meen ik te mogen stellen, dat veeleer sprake is van een combinatie van beide methoden, waarbij nu eens de verbandscontrole dan weer het steunen op de interne controle overweegt.

Er zijn zelfs gevallen waarin interne controle geheel ontbreekt en een verbandscontrole tot voldoende resultaten leidt en anderzijds gevallen waarin wegens het ontbreken van een goederenbeweging of quasi-goederenbeweging het volle accent valt op het steunen op de interne controle.

Daarbij valt nog het volgende te overwegen.

a. Mathematische steekproeven - bij Diephuis een paradepaardje van zijn „nieuwere inzichten" - kunnen ook bij de verbandscontrole toepassing vinden en daar tot aanzienlijke werkbesparing leiden, met name bij de controle van de inkopen en de inventarisaties.

b. Noch de oude noch de nieuwe methode kan zekerheid verschaffen over het zgn. „chiffre d'affaires" (het niveau van het feitelijk bedrijfsgebeuren): - de oude methode niet, omdat een stuk omzet (van inkopen tot en met ontvangst van debiteuren) geheel buiten de verantwoording kan zijn gelaten;

- de nieuwe methode niet, omdat een integrale samenspanning tussen functionarissen kan hebben plaatsgevonden.

Het komt mij voor, dat in beide gevallen praktisch sprake moet zijn van fraude tot in de hoogste leiding en dat de accountant voor zulke fraude (als verondersteld volmaakt bedreven!) niet verantwoordelijk kan worden gesteld.

Anderzijds zou zulke fraude, op gebrekkige wijze uitgevoerd, misschien anders-gerichte kansen op ontdekking opleveren, maar niet bewezen kan worden dat één der beide methoden irl het algemeen betere kansen schept.

$\mathrm{Bij}$ deze laatste overweging speelt mee, dat de accountant alleen verantwoordelijk is voor ontdekking van die fraude, welke bij een controle, niet op fraude gericht, aan het licht zou moeten treden.

Aanvaardt men de generieke gelijkwaardigheid van de oude en nieuwe methode, waarbij in gecombineerde toepassing elks bijdrage afhankelijk is van de aard en omvang van het controle-object, dan moet een vraagteken 
worden gezet bij de motivering van de non-opinion, vanuit ,de aard van het bedrijf", of ,de aard en de omvang van het bedrijf" die een ,onvoldoende" mogelijkheid schept tot het maken van functiescheidingen en het organiseren van een daarop gebaseerde interne controle (of mededelingen van gelijke strekking).

Immers is het veelal mogelijk, en juist dáár waar functiescheidingen niet of onvoldoende kunnen worden toegepast, langs de weg van de verbandscontrole een voldoende, gelijkwaardige zekerheid te verkrijgen.

Geen absolute zekerheid! Maar dat is ook niet het geval met de ,moderne" methode van waarneming via toetsing van systeem en werking van de interne controle.

Het mag de verdienste heten van de voorvechters van de „,nieuwe inzichten" (Diephuis, Tempelaar, e.a.), dat zij het begrip „waarneming” hebben gehaald uit de positivistische dwangbuis van de zgn. ,eigen” waarneming via de controle met ,,stukken van derden" (in wezen ook een afgeleide waarneming!) en dat zij mede hebben bijgedragen tot de evolutie van de garantiegedachte naar die van een controle die het karakter draagt van een diagnose.

Door echter de methode van het steunen op een waargenomen systeem van interne controle nu als de enig zaligmakende te beschouwen en die van de verbandscontrole af te zweren als ouderwets of - eufemistisch - als ,klassiek", hebben zij het beroep bepaald geen dienst bewezen.

Enerzijds heeft dit er toe geleid, dat de accountant ook bij de kleinere en middelgrote bedrijven aan de administratieve organisatie eisen ging stellen, waaraan deze onmogelijk konden voldoen. Het zijn juist deze bedrijven die zich veelal duidelijk richtende op een bijzonder (fysiek) deel van de maatschappelijke voortbrenging - als het ware van nature geschikt zijn voor waarneming via de verbandscontrole. Anderzijds leidde deze eenzijdige propaganda tot een vlucht uit de functie, doordat de accountant de oordeelonthouding ging toepassen, ook daar waar hij met een verbandscontrole voldoende zekerheid had kunnen krijgen.

Hoe sterk deze eenzijdige propaganda heeft doorgewerkt, moge blijken uit „Behandeling", waarin als enig voorbeeld van een objectieve verhindering van controle-technische aard wordt genoemd (blz. 167):

„... de onmogelijkheid tot een stellig oordeel omtrent de volledigheid van een opbrengstverantwoording te komen in een huishouding van zo geringe omvang dat een doeltreffende interne controle niet op economisch verantwoorde wijze kan worden georganiseerd" (cursivering van mij, R.).

Ook Prof. A. B. Frielink in ,,de gbr verklaard” geeft van deze eenzijdigheid blijk in zijn voorbeeld van de formulering van een oordeelonthouding (blz. 48):

,Aard en omvang van de onderneming maken het niet mogelijk zodanige functiescheidingen aan te brengen dat mede daarop een onderzoek kan worden gebaseerd. Dientengevolge kunnen wij geen oordeel uitspreken omtrent de volledigheid der in de jaarrekening opgenomen baten en lasten en derhalve evenmin omtrent de getrouwheid van de jaarrekening als geheel".

Men kan hierbij de vraag stellen of de redegeving van de onzekerheden in de verklaring van oordeelonthouding een plaats behoort te hebben; hierop 
kom ik hierna nog terug.

Voorts valt in beide voorgaande citaten op, de suggestie dat het chiffre d'affaires door de waarneming via de interne controle kan worden vastgesteld; in het voorgaande heb ik daarover reeds mijn ernstige twijfel uitgesproken (los van het feit, dat aan de theoretische eisen aan de interne controle gesteld, in de praktijk zelden of nooit geheel wordt of kan worden voldaan).

Merkwaardig is, dat Abr. Mey de uitdrukking ,chiffre d'affaires" oorspronkelijk slech ts heeft gebruikt, om de volledige controle van de inkopen, in het kader van de verbandscontrole, te bepleiten. Nadien is hiervan door de „modernen" een afzonderlijk probleem gemaakt onder de term „volledigheid" van de opbrengsten resp. ontvangsten, hetgeen is te begrijpen uit hun eenzijdige opvatting, dat alleen via administratie en interne controle een vakkundige waarneming mogelijk is.

Bij die zgn. ,analy tische” methode immers worden ook de opbrengsten c.q. ontvangsten als fragment d.i. in beginsel buiten het verband van inkopen, produktie voorraden, enz. bepaald (de ,cijferbeoordeling”, die in wezen bestaat uit het leggen van verbanden, heeft wel een belangrijke doch secundaire betekenis), terwijl zij bij de verbandscontrole (waaraan ten onrechte de kwalificatie ,analytisch" is ontzegd) in beginsel rekenkundig voortvloeien uit hun verband met de ,waargenomen" inkopen, voorraden, enz.

Het ware te overwegen, de begrippen „chiffre d'affaires”, en „volledigheid" naast ,juistheid" als onhanteerbaar te laten vallen.

Waar het echter hier op aankomt is, dat de mogelijkheid om langs de weg van de ,klassieke" verbandscontrole tot redelijke resultaten te komen, zelfs niet in overweging is genomen. Het is daarom verheugend, dat de discussie over de betekenis van zowel de "klassieke" als de "moderne" controlemethode opnieuw en op zulk een bekwame wijze door Nordemann (MAB 1974) en Blokdijk (idem 1975) is geopend.

Een bespreking van hun beschouwingen valt buiten het bestek van het onderhavige onderwerp. I $\mathrm{k}$ beperk $\mathrm{mij}$ hier tot het uitspreken van de verwachting dat een verdere synthese - waarbij het begrip ,eigen actie” geheel komt te vervallen, de eigen waarneming zijn relatief bescheiden plaats gaat innemen en de onafhankelijkheid van het oordeel haar primaat zal herwinnen - er toe zal bijdragen, dat van de non-opinion in de toekomst geen onnodig gebruik, d.i. geen misbruik wordt gemaakt.

\section{De woordkeuze bij een oordeelonthouding}

Met betrekking tot de formulering van de verklaring van oordeelonthouding bevatten de GBR twee voorschriften (artikel 14, lid 3):

1 opneming van de zinsnede, geen oordeel omtrent de getrouwheid van (aanduiding van de verantwoording) als geheel";

2 vermelding "omtrent welke aangelegenheden onzekerheid bestaat".

Wat is in het tweede voorschrift onder ,,aangelegenheden" te verstaan?

Blijkens „Behandeling” is over artikel 14 GBR uitvoerig gediscussieerd, doch over het begrip ,,aangelegenheden" is slechts één passage, in de toelichting, te vinden (blz. 167): 
„Veelal zal met name de onzekerheid omtrent volledigheidsaspecten bestaan; verwacht mag worden dat de registeraccountant daarvan in voor degenen voor wie de verklaring bestemd is begrijpelijke formulering, melding maakt."

De hier uitgesproken verwachting mocht niet worden gekoesterd. Integendeel brengt reeds de verwijzing naar volledigheidsaspecten de accountant in de verleiding, zich uit te leven in vaktechnische beschouwingen, in plaats van zich rechtstreeks te richten en te beperken tot de belangrijke onderdelen van de verantwoording zelve, waarop de onzekerheden betrekking hebben.

Frielink (t.a.p. blz. 48) stelt eerst (terecht) de eis, dat uit de verklaring de aangelegenheden ,waarover" onzekerheid bestaat, duidelijk moeten blijken.

Daarna geeft hij echter een voorbeeld - ten onrechte de duidelijkheid stellende tegenover de beknoptheid - waarin de vaktechnische oorzaken van de onzekerheid voorop worden gesteld, waarna een omschrijving volgt van de aangelegenheden waarop de onzekerheden betrekking hebben:

„Aard en omvang van de onderneming maken het niet mogelijk zodanige functiescheidingen aan te brengen dat mede daarop een onderzoek kan worden gebaseerd. Dientengevolge kunnen wij geen oordeel uitspreken omtrent de volledigheid der in de jaarrekening opgenomen baten en lasten en derhalve evenmin omtrent de getrouwheid van de jaarrekening als geheel."

Beknoptheid, door het achterwege laten van de eerste volzin, zou de duidelijkheid daarvan voor de verstandige leek ten goede komen. Deze lezer immers is alleen geinteresseerd in de vraag of de verantwoording getrouw is. Als de accountant daar blijkens zijn oordeelonthouding geen antwoord op kan geven, maakt het voor die lezer weinig uit wat de vaktechnische oorzaken van die aordeelonthouding zijn, nog daargelaten dat hij de implicaties van de algemene omschrijving niet kan beoordelen.

Anderzijds zou de duidelijkheid van de verklaring aanzienlijk kunnen worden verbeterd, door nauwkeurig aan te geven om welke details (in het voorbeeld van Frielink: welke baten en lasten) het gaat.

Wanneer details niet afzonderlijk uit de verantwoording blijken, kunnen zij in de verklaring worden opgenomen; zulke vermelding heeft uiteraard een ander karakter dan de omschrijving van de draagwijdte van een voorbehoud (artikel 14, lid 1, GBR), omdat daar die draagwijdte door de accountant is vastgesteld; o.a. wanneer dit laatste niet mogelijk is, moet de accountant zijn toevlucht nemen tot de oordeelonthouding. Uit Frielink's algemene omschrijving van de aangelegenheden (alle baten en lasten) krijgt men de indruk dat de controle integraal onuitvoerbaar was en vraagt men zich af of een non-audit opdracht c.q. -mededeling dan niet meer voor de hand zou liggen.

Ter voorkoming van misverstand wil ik er gaarne nog op wijzen, dat het verstrekken van een aldus verkorte en op de ,,aangelegenheden" toegespitste verklaring, de accountant niet er van behoeft te weerhouden, de verantwoordingsplichtige en diens deskundigen in te lichten over de vaktechnische achtergronden. Hiertoe bestaat altijd gelegenheid op een andere plaats in het rapport of door afzonderlijke schriftelijke of mondelinge adviezen. 


\section{Kan de verantwoording ,overigens getrouw" zijn?}

In vele verklaringen van oordeelonthouding treft men mededelingen aan als: "- dat ons overigens van onjuistheden in de verantwoording niet is gebleken" of (niet ter zake):

„dat ons overigens van onjuistheden in de administratie niet is gebleken".

Zulke mededelingen vloeien voort uit de wens van de verantwoordingsplichtige, aan zijn verantwoording nog zoveel mogelijk betekenis te geven en uit de wens van de accountant, het nut van zijn arbeid nog zoveel mogelijk waar te maken. Beide wensen zijn begrijpelijk en op zichzelf aanvaardbaar.

Niettemin is het de vraag of mededelingen van deze aard passen in de verklaring van oordeelonthouding.

Met Frielink (t.a.p. blz. 48) beantwoord ik deze vraag ontkennend.

Frielink maakt hierbij een ,uitzondering” voor de bijzondere onderzoekingen, doch deze hebben met dit vraagstuk niets te maken, omdat de oordeelonthouding altijd een verklaring is aangaande een verantwoording als geheel. Met andere woorden de artikelen 12 tot en met 14 GBR hebben op bijzondere onderzoekingen als zodanig geen betrekking of alleen als uit de opdracht (mede) voortvloeit dat een oordeel moet worden gegeven over de getrou wheid van een verantwoording.

Terecht stelt Frielink dat de bestreden mededeling niets aan de strekking van de verklaring toevoegt of (daardoor?) een groter vertrouwen wekt dan gerechtvaardigd is.

Alweer is van doorslaggevende betekenis dat het oordeel betrekking heeft op de verantwoording als geheel. Toch is hiermede de zaak nog niet geheel bekeken. Want men zou de vraag mogen stellen of bij deze strekking van de verklaring óók de ,,aangelegenheden waarover onzekerheid bestaat" eigenlijk niet irrelevant zijn!

Ook het verband tussen de onzekerheden over de details en de onzekerheid'ten aanzien van de verantwoording als geheel is iets, dat de accountant voor zichzelf als onafhankelijk vakman moet beoordelen.

Ten hoogste is het voorschrift van de vermelding van de ,,aangelegenheden" waaromtrent onzekerheid is blijven bestaan, te motiveren uit het nieuwe begrip van verklaring: de mededeling omtrent de uitkomst (in de beteken is van resultaat) van de verrichte onderzoekingsarbeid.

De innerlijke tegenspraak tussen de verklaring van oordeelonthouding en de eigenlijke functie van een verklaring (het oordeel over de getrouwheid van een verantwoording) blijft derhalve bestaan.

Een beperkter gebruik van de non-opinion dan thans het geval is, ware daarom wenselijk. In elk geval is een van jaar tot jaar voortgezette nonopinion bij de verantwoording van dezelfde huishouding geen optreden dat het aanzien van het openbare beroep bevordert. Indien de objectieve verhinderingen blijken, ook bij voortduring niet te kunnen worden weggenomen, is een controle-opdracht een zinloze zaak en is een non-audit opdracht de enig aanvaardbare. 


\section{Samenvatting}

1 De introductie van de verklaring van oordeelonthouding in de beroepsregelen hangt samen met het nieuwe begrip ,verklaring", t.w. de verantwoording van het resultaat van de onderzoekingsarbeid.

$2 \mathrm{Zij}$ dreigt veelvuldig te worden gebruikt en schept de meeste problemen.

3 Het onderscheid met de non-audit mededeling is scherp en moet consequent worden toege past.

4 De WJO voorziet in de oordeelonthouding, maar niet in de non-audit.

5 Bij het tegelijk vóórkomen van onzekerheden en bedenkingen prevaleert de oordeelonthouding boven de afkeuring.

6 De oordeelonthouding houdt niet eenzijdig verband met de mogelijkheid tot het steunen op de interne controle. Theorie en praktijk van de verbandscontrole zijn nog springlevend.

7 De vaktechnische oorzaken van de onzekerheden vinden in de verklaring van oordeelonthouding geen plaats.

8 De innerlijke tegenspraak in de verklaring van oordeelonthouding blijft bestaan. Haar toepassing blijve incidenteel.

januari 1976 